\title{
GETTING A COMPLEX MASTER ALLOY FOR ALLOYING HIGH-MANGANESE STEELS AND CAST ALUMINUM ALLOYS
}

\author{
${ }^{1}$ Mykhailo VORON, ${ }^{2}$ Yuriy KOSTETSKY, ${ }^{1}$ Marina FON PRUSS \\ ${ }^{1}$ Physical and technological institute of metals and alloys, NAS of Ukraine Kyiv, Ukraine, \\ mihail.voron@gmail.com,m.fonpruss@gmail.com \\ ${ }^{2}$ National Technical University of Ukraine "Igor Sikorsky Kyiv Polytechnic Institute", Kyiv, Ukraine, \\ sm@fhotm.com
}

https://doi.org/10.37904/metal.2020.3458

\begin{abstract}
The work is dedicated to obtaining a complex Al-Mn-Fe master alloy for precise alloying high-manganese steels with aluminum high content as well as for making additions during aluminum alloys production. The addition of aluminum large quantity to steel during steelmaking is an especially difficult task, because of the low density and melting temperature of aluminum. A complex Al-Mn-Fe master alloy with more high density and melting temperature then aluminum may be proposed as an alternative for metal aluminum at precise steel alloying. Such master alloy also may be useful for preparing traditional cast aluminum alloys and special creep-resistant Al-based alloys. In this investigation, the master alloy was prepared via electron-beam casting technology (EBCT) with using cheap raw materials like ferromanganese and aluminum scrap. It was established there is a possibility to obtain an alloy with a high content of main components and low content of carbon due to the process peculiarities. The prepared master alloy Al-17Mn-4Fe has a density of $3.8 \mathrm{~g} / \mathrm{cm}^{3}$ and a specific structure, that contains phases with a significantly higher melting point than pure aluminum.
\end{abstract}

Keywords: Master alloy, high-manganese steel, alloying, aluminum, electron-beam casting technology

\section{INTRODUCTION}

During the last decade, a lot of attention was paid for problems connected with high-strength austenitic steels with twinning induced plasticity (TWIP) for automotive and other industries. Such steels have high hardening properties, excellent ductility (up to $95 \%$ ), and may significantly reduce the weight of constructions [1-5]. Usually, they can contain (wt. \%) 17-34 Mn, 3-14 Al, 1-3 Si, 0.01-1 C [5-7].

But a lot of specific problems arise in their production. In particularity, a necessity alloying with a significant amount of manganese and aluminum causes problems during steelmaking. Using of ferroalloys has limitations because of high carbon content, phosphorous presence, and some other admixtures. For example, ferromanganese may contain 1-8 wt. \% of carbon, ferrosilicon may contain $0.2-1 \% \mathrm{wt}$. of carbon, ferroaluminum may contain up to $0.2 \% \mathrm{wt}$. of carbon and up to $0.5 \% \mathrm{wt}$. of copper. The phosphorous content in these ferroalloys may vary from $0.05 \%$ wt. to $0.7 \%$ wt. On the whole that limiting to use them for the final precise adjusting of the chemical composition of steels.

As a rule, aluminum added for alloying in the form of pure metal, but in case of introducing large portions, some technical problems caused by aluminum physical properties arise. The most widely used method for precise alloying steels with active elements consists of using a feeding wire. The wire may be filled with alloying elements, compacted inside an iron shell. But in some cases, using bulk parts of master alloys is preferable including for steel alloying with aluminum. That makes the task of developing special master alloys on the base of aluminum and technologies for their preparation relevant. 
Such master alloys also may be very useful for producing Al-based alloys. New machines and constructions require new heat resistant aluminum alloys and their creation is connected with a significant content of Fe and $\mathrm{Mn}$. Such alloys mostly belong to casting materials, so they have to consist of eutectics. At the same time, alloying components should be almost insoluble in matrix metal and form intermetallic phases, stable up to $450{ }^{\circ} \mathrm{C}$ and higher. [8-11]. Manganese, iron, nickel, cobalt, and a few other elements are mostly attractive for achieving such goals. Thus, the production of not very expensive master alloys with a high amount of main alloying components is an important task too.

In this regard, the possibility of obtaining a complex Al-Mn-Fe master alloy for precise alloying via electronbeam casting technology (EBCT) was explored. The EBCT technology was developed in the Physical and technological institute of metals and alloys (National academy of science of Ukraine) refers to vacuum technologies, which uses a high energy independent heating source [12]. The method provides an ability of selective melting of metal charge components that were charged together. Melt homogenization provides by an electro-magnetic stirring system, which is important when remelting compounds with sharply different densities.

The main idea was to obtain Al-Mn-Fe master alloy by remelting a cheap charge, composed of ferroalloys and different kinds of scrap, with maximal manganese assimilation and carbon removing.

\section{EXPERIMENTAL PROCEDURE AND RESULTS}

EBCT was used to prepare Al-Mn-Fe master alloy with using ferromanganese FeMn75 and waste electrotechnical aluminum. Graphite crucible with the charge was deposited inside the water-cooling section copper holder. The melting process occurred slight growth of electron-beam heating power from 10 to $45 \mathrm{~kW}$. Liquid melt has been sintered for 10 minutes under average e-beam heating power about $40 \mathrm{~kW}$.

Because of $\mathrm{Mn}$ high evaporation rate under vacuum and high carbon content in ferromanganese (up to 6-8 wt.\%) special technological decisions were necessary. EBCT method allowed us to meet the tasks via its specific technological abilities, such as independent heating source and electromagnetic stirring, which provides significant local overheating of melt under continuous heat-mass transfer. During the process, heavy Fe-Mn parts of charge are deposited at the bottom of the crucible and covered by liquid aluminum. That protects $\mathrm{Mn}$ from rapid evaporation. The energy efficiency of the whole process is quite high because of low needed energy and high heat isolation.

Aluminum has been deposited at the bottom or graphite crucible ferromanganese - at the top of the aluminum charge. The melting process included crucible preheating at the same time with ferromanganese due to the ebeam scanning regime. After aluminum started melting, e-beam was focused at the center of the crucible. Then, overheating to $800-900^{\circ} \mathrm{C}$ was provided at the same time with electromagnetic stirring. Convective melt flows a high temperature-induced $\mathrm{Fe}$ and $\mathrm{Mn}$ diffusion into liquid aluminum. Heavy carbides and light-weight oxides were separating from a liquid melt, according to treatment time and temperature. The top layer of insoluble admixtures was protecting $\mathrm{Al}$ and $\mathrm{Mn}$ from intensive evaporation. After reaching a temperature of about $1,100-1,200^{\circ} \mathrm{C}$, the liquid melt has been poured into a steel mold. Cylindrical ingot with $38 \mathrm{~mm}$ diameter and $320 \mathrm{~mm}$ length has been obtained (Figure 1). It contained (wt. \%) Al-17Mn-4.2Fe and its density was 3.8 $\mathrm{g} / \mathrm{cm}^{3}$.

Structure and phase composition of the obtained ingot was also explored. The specimen was taken from the central part of the ingot, ground, polished, and itched in acid solution: $94 \mathrm{ml} \mathrm{H}_{2} \mathrm{O}, 2.5 \mathrm{ml} \mathrm{H}_{2} \mathrm{SO}_{4}, 2 \mathrm{ml} \mathrm{HCl}, 1$ $\mathrm{ml} \mathrm{HNO} 3,0.5 \mathrm{ml} \mathrm{HF}$. The microstructure was evaluated by using SEM Tescan Vega-3, equipped with Bruker console, that makes able to investigate the local chemical composition of structural elements. Structures are shown in Figure 2 and local chemical composition is given in Table 1. 


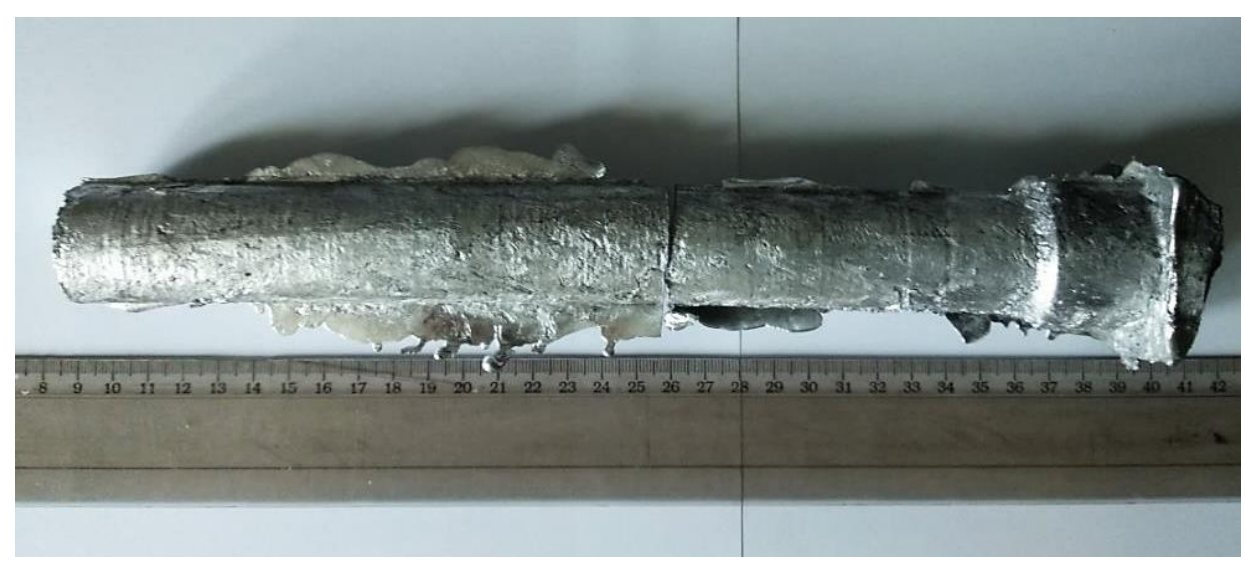

Figure 1 Experimental Al-Mn-Fe master alloy ingot

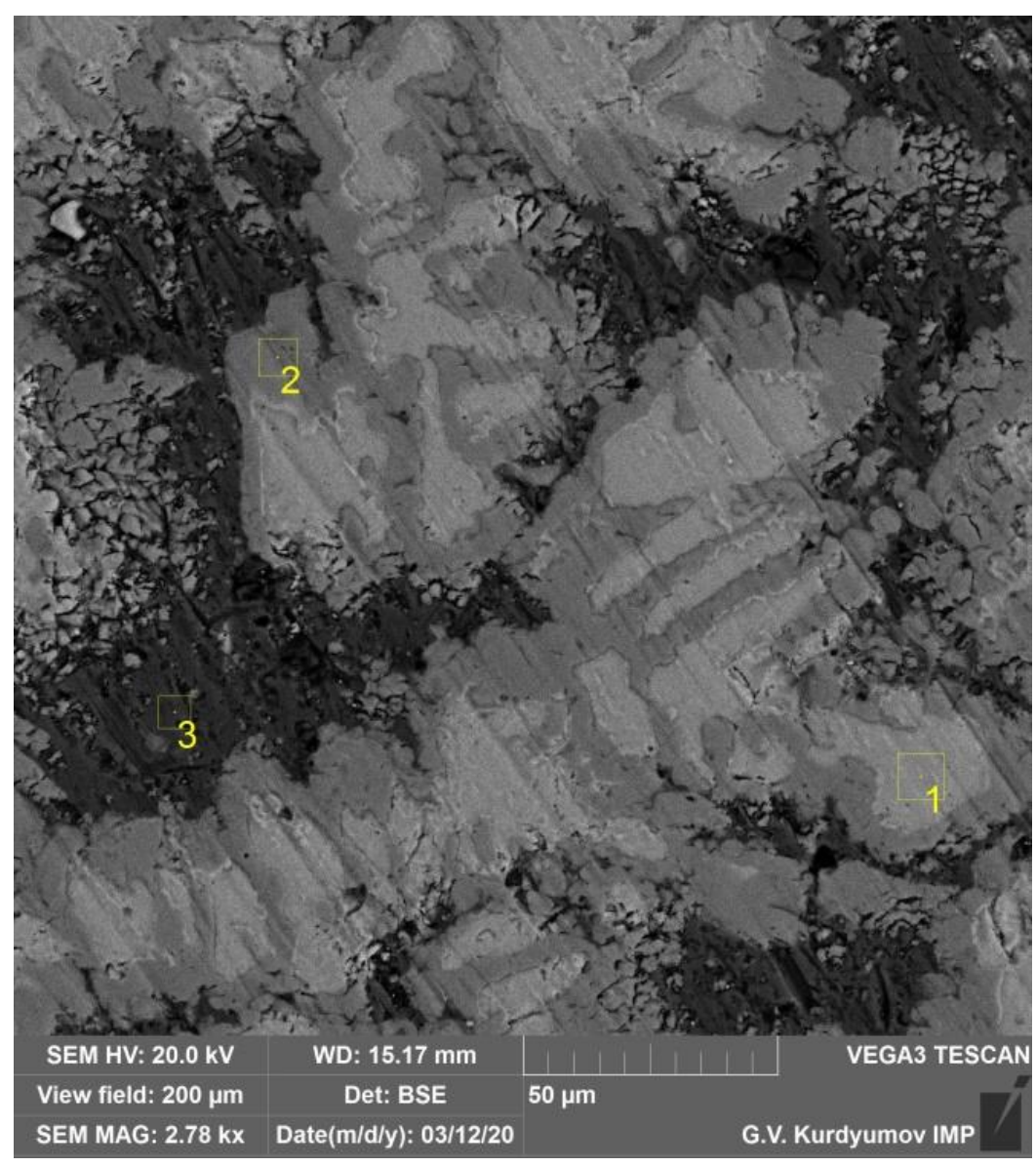

Figure 2 Microstructure of master alloy in back scattered electrons with marked areas for local chemical composition investigation

Table 1 Chemical composition of phases, according to marked areas

\begin{tabular}{|c|c|c|c|c|c|c|}
\hline \multirow{2}{*}{ Point } & \multicolumn{5}{|c|}{ Elements (wt. \%) } & \multirow{2}{*}{ Phase (1) } \\
\cline { 2 - 7 } & $\mathbf{A l}$ & $\mathbf{F e}$ & $\mathbf{M n}$ & $\mathbf{M g}$ & $\mathbf{S i}$ & \\
\hline 1 & 59.6 & 8.02 & 30.4 & 0.22 & 0.38 & $\mathrm{Y2}_{2}-\mathrm{Al}_{8}(\mathrm{MnFe})_{5}$ \\
\hline 2 & 72.24 & 5.44 & 20.84 & 0.3 & - & $\mathrm{HT}^{-} \mathrm{Al}_{11}(\mathrm{MnFe})_{4}$ \\
\hline 3 & 95.77 & 0.24 & 1.8 & 0.3 & 0.1 & Al-based solid solution \\
\hline
\end{tabular}


The master alloy structure consists mainly of three zones. Dendritic-like grains have a composite structure when the most high-temperature phase is coated by the familiar phase, formed mainly because of the concentration gradient, which was forming during crystallization. Due to chemical composition, it seems, that areas 1 and 2 seem to match $\mathrm{Y}_{2}-\mathrm{Al}_{8} \mathrm{Mn}_{5}$ and $\mathrm{HT}-\mathrm{Al} 11(\mathrm{MnFe})_{4}$ phases respectively [13]. Such phases can content some volumes of $\mathrm{Fe}$. There are two very important features about $\mathrm{y}_{2}$ and $\mathrm{HT}$ phases - they are stable up to $\sim 1,000{ }^{\circ} \mathrm{C}[13,14]$ and they are surrounding significant volumes of aluminum.

X-ray diffraction analysis was performed by Rigaku Ultima IV device. It confirmed the presence of hightemperature $\mathrm{Y}_{2}$ and $\mathrm{HT}$ phases and also showed the absence of carbides and oxides inside master alloy specimens.

Such characteristics are useful to prevent the quick dissolution of master alloy bulk in top layers of slag or liquid steel while alloying. At the same time, small grain size $(50-250 \mu \mathrm{m})$ may provide quick assimilation of alloying elements after the feeding master alloy piece is melted. Such characteristic is also useful for Al-based alloys, which have an average melt preparing temperature around $820-850^{\circ} \mathrm{C}$.

\section{CONCLUSIONS}

Low density, melting point, and high reactivity of aluminum complicates its insertion and assimilation in liquid steel. To improve the effectiveness of the high-manganese steels alloying with aluminum it is proposed to use Al-Mn-Fe master alloys.

In laboratory conditions, $\mathrm{Al}-17 \mathrm{Mn}-4 \mathrm{Fe}$ master alloy was obtained via the EBCT technic with using cheap raw materials. In experiments, electrotechnical aluminum scrap and screenings of ferromanganese were used as a charge, which is significant from the point of the final product cost.

The EBCT technic provides good enough assimilation of manganese from a charge.

The obtained metal had a relatively high density of $3.8 \mathrm{~g} / \mathrm{cm}^{3}$. Phase composition referred by two connected high-temperature phases $\mathrm{\gamma}_{2}-\mathrm{Al}_{8} \mathrm{Mn}_{5}$ and $\mathrm{HT}-\mathrm{Al}_{11} \mathrm{Mn}_{4}$, which are stable up to $\sim 1,000^{\circ} \mathrm{C}$. They also are surrounded by some volumes of aluminum, which may prevent its quick melting and dissolution after master alloy addition inside the liquid steel.

Supposed to that such Al-Mn-Fe master alloys may also be helpful in producing the new creep-resistant Albased alloys.

\section{REFERENCES}

[1] LI, K., ZHUANG, Ch., LIU, J., JI, Yi., HAN, Zh. Smelting and casting technologies of Fe-25Mn-3Al-3Si twinning induced plasticity steel for automobiles. Journal of Iron and Steel Research. 2015, vol. 22, pp. 75-79.

[2] RANA, R., LAHAYE, C., RAY, R. Overview of Lightweight Ferrous Materials: Strategies and Promises. Journal of metals. 2014, vol. 66(9), pp. 1734-1746.

[3] MA, L., WEI, Y., HOU, L., YAN, B. Microstructure and Mechanical Properties of TWIP Steel Joints. Journal of Iron and Steel Research. 2014, vol. 21, pp. 749-756.

[4] KOYAMA, M., SAVAGUCHI, T., OGAVA, K., KIKUCHI, T., MURAKAMI, M. The effects of thermomechanical training treatment on the deformation characteristics of Fe-Mn-Si-Al alloys. Materials Science and Engineering A. 2008, vol. 497, pp. 353-357.

[5] FROMMEYER, G., BRUX, U., NEUMANN, P. Supra-Ductile and High-Strength Manganese-TRIP/TWIP Steels for High Energy Absorption Purposes. ISIJ International. Vol. 43, pp. 438-446.

[6] DAI, Y., MI, Z., TANG, D., JIANG, H., LI, S. Microstructure and mechanical properties of the Fe-Mn-C TWIP steel. Shanghai Steel. 2007, vol. 29, pp. 132-136. 
[7] KOYAMA, M., SAWAGUCHI, T., LEE, T., LEE, C., TSUZAKI, K. Work hardening associated with $\varepsilon$-martensitic transformation, deformation twinning and dynamic strain aging in Fe-17Mn-0.6C and Fe-17Mn-0.8C TWIP steels. Materials Science and Engineering A. 2011, vol 528, pp. 7310-7316.

[8] RAJAN, R., KAH, P., MVOLA, B., MARTIKAINEN, J. Trends in aluminium alloy development and their joining methods. Reviews on Materials Science. 2016, vol 4 (44), pp. 383-397.

[9] KASPZAK, W., EMADI, D., SAHOO, M., ANIOLEK, M. Development of Aluminium alloys for high temperature applications in diesel engines. Materials Science Forum. 2009, Vol. 618-619. pp. 595-600.

[10] TANAKA, T., TAMITAKAKARA, Y. Highly heat-resistant aluminum alloy "KS2000". KOBELCO technology review. 2017, vol. 35, pp. 28-33.

[11] GORBUNOV, J. Main Characteristics and future development of aluminum alloys with high dispersion ability of phase of alloying elements. Journal of Siberian Federal University. Engineering and Technologies. 2014, vol. 5, pp. 570-578.

[12] LADOKHIN, S.V. et al Electronno luchevaya plavka $v$ liteinom proizvodstve. Kyiv: Stal, 2007.

[13] BALANETSKYY, S., PAVLYUCHKOV, D., VELIKANOVA, T., GRUSHKO, B., The Al-rich region of the Al-Fe-Mn alloy system. Journal of Alloys and Compounds. 2015, vol. 619, pp. 211-220.

[14] PRIPUTEN, P., ČERNIČKOVÁ, I., LEJČEK, P., JANIČKOVIČ D., JANOVEC, J. A Partial Isothermal Section at $1000^{\circ} \mathrm{C}$ of Al-Mn-Fe Phase Diagram in Vicinity of Taylor Phase and Decagonal Quasicrystal. Journal of Phase Equilibria and Diffusion. 2015, vol. 37, pp. 130-134. 